\title{
Treinamento para equipes de atendimento de uma Instituição de Ensino Superior do interior de Minas Gerais
}

\author{
DOI: 10.47224/revista master.v6i11.111
}

\author{
Danilo Faria de Moura \\ Kenia de Lima Mundim \\ Lucy de Melo \\ Lilian Tae Hamada \\ Emanuel Soares Ponciano
}

e-mail:danilofmoura@yahoo.com.br

\section{Resumo}

Como consequência da evolução tecnológica os produtos e serviços oferecidos pelas empresas estão cada vez mais se equiparando a modelos similares, nesse contexto o atendimento ao cliente se torna um diferencial de sucesso na fidelização e atração de clientes. O objetivo desse artigo é detectar e analisar as oportunidades no processo de atendimento ao cliente em uma instituição de serviços educacionais e, através delas, propor soluções. Utilizou-se da Metodologia do Arco de Maguerez que possibilitou a estruturação das propostas de intervenção partindo da observação da realidade. O embasamento teórico se deu por meio de uma pesquisa bibliográfica referente aos assuntos apresentados. Frente aos problemas detectados foi proposto a realização de uma trilha de treinamentos, porém em virtude da pandemia da COVID-19 não foi possível sua realização de fato, sendo considerado, assim, uma proposta de intervenção para um momento mais oportuno. Compreende-se que a dimensão e potencial do atendimento para fidelização, retenção e busca de novos clientes, também se faz presente no segmento educacional.

Palavras-chave: Atendimento ao cliente; Treinamento; Satisfação do cliente.

\begin{abstract}
As a results of technological evolution, the products and services offered by companies are more and more equating to similar models, during this context, customer service becomes a hit differential in customer loyalty and attraction. the aim of this text is to detect and analyze opportunities within the customer service process in an academic services institution and, through them, solutions. The Arch Methodology of Maguerez was used, which enabled the structuring of intervention proposals supported the observation of reality. The theoretical basis was given through a bibliographical research pertaining to the addressed subjects. in sight of the issues detected, it had been proposed to hold out a training trail, but thanks to the COVID-19 pandemic, it had been impossible to truly carry it out, thus being considered an intervention proposal for a more opportune moment. it's understood that the dimension and repair potential for loyalty, retention and look for new customers is additionally present without an academic segment.
\end{abstract}

Keywords: $\quad$ Customer service; Training; Customer satisfaction.

\section{INTRODUÇÃO}

Segundo Chiavenato (2009, p. 288) "o treinamento é o processo educacional, aplicado de maneira sistêmica, através do qual as pessoas aprendem conhecimentos, atitudes e habilidades em função de objetivos definidos."

Para Hamblin (1978, p. 15) "o treinamento abrange qualquer tipo de experiência destinada a facilitar um ensino que será útil no desempenho de um cargo atual ou futuro."

Pela definição de ambos é possível verificar que o treinamento é algo para curto prazo, em que se espera um resultado rápido através da aplicação de algum tipo de conhecimento visando resolver, corrigir ou sanar algum tipo de problema.

Um dos setores que apresenta a necessidade de treinamentos pontuais, rápidos e com resultados 
significativos é o atendimento ao cliente, pois sofre muitas interferências dos ambientes externos, independente do setor de atuação das empresas. Sobre o atendimento ao público, pode-se entender que:

O atendimento ao público é uma das atividades de maior relevância em uma empresa no que diz respeito com o trato ao cliente, por isso é tão importante para as organizações, estando presente em diversas discussões. Trata-se da forma como todos os funcionários interagem com o cliente, ou seja, o público, e fazem parte desse processo todas as pessoas que mantêm algum tipo de relacionamento com a empresa. TANI $(2018$, p. 12)

O presente estudo é resultante das atividades desenvolvidas no Curso Gestão de Recursos Humanos, no componente curricular "Projeto Integrador: Desenvolvimento de $\mathrm{RH}^{\prime \prime}$, terceiro período, do primeiro semestre de 2020. Seu desenvolvimento se deu por meio da Metodologia da Problematização com o Arco de Maguerez. O embasamento teórico se deu por meio de uma pesquisa bibliográfica referente aos assuntos apresentados. O recorte da realidade contempla a análise de equipes de atendimento de uma empresa privada de educação superior,

Objetiva-se, por meio desse estudo, detectar e analisar as oportunidades no processo de atendimento ao cliente para propor soluções através de treinamentos específicos para os colaboradores que exercem essa atividade.

Tani (2018, p. 11), destaca que "a impressão que a empresa deve deixar ao atender o público é a do bom atendimento, da cordialidade e do profissionalismo, isso porque uma pessoa mal atendida comentará sobre essa situação com os seus pares, como forma de protesto, o que pode se transformar em perda de clientes."

$\mathrm{O}$ atendimento ao cliente se torna um grande diferencial para a escolha de um aluno pela instituição de ensino, mesmo que esse atendimento às vezes não seja prestado diretamente ao aluno. Tani $(2018$, p. 12) relembra que "não importa se o cliente vai ou não comprar, o que importa é que ele tenha uma imagem positiva da empresa, às vezes, a pessoa entra em um lugar apenas para conhecer, saber o preço ou pedir uma informação, porém, essa pessoa pode se tornar um cliente em potencial."

Mesmo com todo planejamento que a empresa faz para a contratação de pessoas com perfil para prestação do melhor atendimento possível, sempre terá que aplicar treinamentos com a finalidade de capacitar e atualizar esses funcionários para o atingimento das metas e excelência no atendimento, considerando, inclusive, que o mundo muda, e as pessoas também, consequentemente suas necessidades.

Tani (2018, p. 14) afirma que "atender bem o público não pode se tornar algo monótono $\mathrm{e}$ rotineiro, a empresa deve sempre reinventar suas formas de atendimento, criando novidades, promoções e formas de encantamento do cliente." A autora ainda relata que empresas estagnadas no trato com o público estão fadadas à obsolescência e à decadência, pois são constantemente sucumbidas pela concorrência. Confirma-se, assim, a necessidade contínua de treinamento e desenvolvimento para as equipes de atendimento, que devem acompanhar a evolução e mudanças das instituições.

Por meio das observações, apresentadas a posteriormente, e das justificativas levantadas, alguns tipos de treinamento poderão ser considerados com objetivo de atender à essa demanda: treinamento on-line, cursos de aperfeiçoamento, palestras motivacionais, workshops, entre outros.

\section{IDENTIFICAÇÃO DA PROBLEMÁTICA}

Faz-se máster ter claro as expectativas dos clientes frente a essa necessidade de corresponder seus interesses.

Mas o que ele espera? Em primeiro lugar: ser ouvido. Aprender a ouvir o cliente é o primeiro passo para que exista a possibilidade de auxílio, de socorro e de observação. Além disso, é preciso aprovar, entender e respeitar o que o cliente está falando, pedindo e expressando. O atendimento trata-se de prestar auxílio, acudir, socorrer, ou seja, é dar uma solução. TANI (2018, p. 15)

Em suma, os clientes buscam agilidade e habilidades de resolução de problemas. 
Quanto mais hábil for o atendente, mais experiente e mais bem treinado ele será, pois, dessa forma, pode identificar as necessidades e começar o envolvimento de solução, antes mesmo do cliente/público terminar de desenvolver o seu raciocínio e definir a sua necessidade. Saber fazer um atendimento rápido não quer dizer ser ineficaz. As técnicas de desenvolvimento e percepção das necessidades fazem que a prática seja aperfeiçoada. TANI (2018, p. 10)

Sobre o setor de atendimento da empresa pesquisada, foi constatado através de uma avaliação interna, on-line, entre os setores, a necessidade de um treinamento para aperfeiçoar o atendimento, pois entre a aplicação de pesquisa de satisfação de um semestre para outro houve queda na satisfação. Pela definição de Tani (2018, p. 9), verifica-se que "o treinamento é algo para curto prazo, em que se espera um resultado rápido através da aplicação de algum tipo de conhecimento visando resolver, corrigir ou sanar algum tipo de problema."

\section{3}

\section{COMPREENSÃO DA REALIDADE}

A empresa analisada, do ramo de educação, realiza vários tipos de atendimento, tanto à alunos, como pais, fornecedores e sociedade. $\mathrm{O}$ atendimento por telefone, feito pela central de atendimento ao aluno, capta e realiza a tratativa de solicitações apresentadas tanto de forma ativas ou receptivas, atendimento que também é realizado virtualmente pelo site da empresa, pelo WhatsApp e por e-mails dos diversos setores. Além desses canais também é realizado o atendimento presencial na instituição.

A instituição realiza pesquisas periódicas de satisfação para suas diversas áreas, não sendo divulgados os resultados externamente para preservação das informações. Para esse estudo, será analisado o atendimento presencial, que tem um estilo diferenciado para atendimento personalizado.

Tani (2018, p. 11) ressalta que "falar de atendimento ao público, ou atendimento ao cliente, é falar da importância que se deve dar às pessoas." Essa atenção deve seguir padrões para que possa atender a todos com o mesmo grau de excelência e prontidão.

Em alguns setores o atendimento diário conta com um grande fluxo de clientes em determinados períodos do mês. Diante disso terá dias que o atendimento será feito com excelência e em outros dias, devido ao grande fluxo, esse atendimento apresenta queda na qualidade. Esses picos de atendimento são sazonais de acordo com as particularidades das solicitações como rematrícula ao fim do semestre letivo, impressão de boletos e pagamentos de mensalidades no início do mês.

A empresa mescla tanto o atendimento presencial quanto os virtuais e conta com vários atendentes de diversos setores para resolver tratativas distintas, relacionados a faturas, históricos, declarações, dúvidas relacionadas ao site, alterações de cadastro, dentre outras. Foi observado alguns fatores agravantes, entre eles o desgaste da equipe de atendimento, excesso de fluxo de pessoas para poucos atendentes, ineficiência no planejamento de atividades e falta de outros tipos de atendimento para auxiliar na desburocratização.

Compreendendo que o atendimento é um canal direto com o cliente, alguns fatores devem ser considerados para a elaboração de um treinamento com a finalidade de estimular a equipe a ser mais calma e paciente, ter atenção e carisma e principalmente agilidade com os diversos problemas e estilos de pessoas que adentram o local.

Assim, alinhados a uma breve introdução sobre a temática com a apresentação de seus objetivos e justificativas, aliado ao relato da observação da realidade, foram identificados os possíveis fatores imediatos e os condicionantes maiores, associados ao problema em questão.

Destacam-se como possíveis fatores imediatos para o atendimento ao cliente nessa instituição:

a) satisfação do cliente comprometida em momentos de picos de fluxos de pessoas;

b) desgaste e estresse $\mathrm{da}$ equipe de atendimento, pois lida com pessoas de todo tipo de humor.

Os possíveis condicionantes maiores relacionados são:

a) atendentes desgastados, necessitando de motivação;

b) baixa quantidade de estímulos de desenvolvimento formal para agilidade na execução das tarefas; 
c) o atendimento presencial lida diretamente com os clientes e seus inúmeros questionamentos e reclamações, exigindo controle emocional e conhecimento técnico para lidar com solicitações diversas;

d) ausência de treinamento para compreender estilos de clientes e como lidar com eles.

A reflexão sobre os fatores imediatos e os condicionantes maiores, associados ao problema, coloca em evidência alguns pontoschave:
a) ausência de treinamento;
b) ausência de gestão de clima pontual para motivação da equipe;
c) atendimento ao cliente com oportunidades de melhorias.

\section{ATENDIMENTO E SATISFAÇÃO DO CLIENTE}

A partir dos pontos-chave, buscou-se uma fundamentação teórica para posterior elaboração de hipóteses de solução para a problemática eleita nesse estudo.

Chiavenato (2009, p. 295), ao se referir sobre valores organizacionais, sinaliza que as organizações priorizam certos valores, como "as pessoas são o ativo mais importante" ou "o cliente sempre tem razão", que funcionam como padrões que orientam o comportamento das pessoas. Na prática, os valores definidos por uma organização podem diferir daquilo que seus dirigentes acreditam ou valorizam no cotidiano.

Treinamento é o processo de desenvolver qualidade nos recursos humanos para habilitá-los a serem mais produtivos e contribui para o alcance de objetivos organizacionais. $\mathrm{O}$ propósito do treinamento é aumentar a produtividade dos indivíduos em seus cargos influenciando seus comportamentos. (CHIAVENATO, 2009, p. 295)

Milkovich e Bourdreau (2010, p. 338) conceituam o treinamento como "um processo sistematizado com o intuito de promover a aquisição de habilidades, regras e atitudes resultando numa melhor adequação entre as características dos colaboradores e as exigências diante de sua função."

Assim sendo, quem define o tipo ou a forma de atendimento que mais agrada é o cliente. Logo, a empresa tem que ter uma visão adequada sobre como facilitar a vida do cliente sem que haja impacto negativo nas questões jurídicas e financeiras, sendo necessário treinar e orientar suas equipes.

Para o encantamento do cliente com agilidade e bom atendimento, Kotler e Armstrong (2003, p. 475) citam que "atrair e reter clientes pode ser uma tarefa difícil. Hoje, os clientes têm à sua disposição uma grande variedade de escolha de produtos e marcas, preços e fornecedores". A partir dessa definição é possível analisar que encantar o cliente é o diferencial para conseguir atrair e reter o cliente.

Tani $(2018$, p. 12$)$ ressalta que "saber ouvir significa mais que escutar. É escutar com atenção, processando o que o outro diz. Em tempos de tantas mudanças, o ser humano tem necessidade cada vez maior de se exprimir, expor suas ideias e de desabafar".

Nessa citação percebe-se que saber ouvir e dar atenção é uma forma de encantar não somente ao cliente, mas ao colaborador também. Clientes e funcionários que tem atenção e alguém para ouvir suas necessidades e atendê-las, com certeza se sentirão mais satisfeitos.

A relação cliente/fornecedor interno é um
dos itens mais sensíveis e importantes no
universo das boas práticas da Empresa-
Rede, pois define o ponto de partida para
que todos estejam unidos e contribuindo
para encantar o cliente externo. O
comportamento deve ser pautado pelo
dever de um ajudar o outro, de cada qual
preocupar-se constantemente com a
qualidade do trabalho que está entregando
e, sobretudo, pela consciência de que o
colega associado precisa receber dos
demais a melhor contribuição naquilo que
deles depender. Isso é fundamental para
que todos geremo melhor resultado para o
cliente externo. (TANI, 2018, p. 9)
BUROCRACIA NO ATENDIMENTO PRESENCIAL

Para Dessler (2003, p. 140), "treinamento é um conjunto de métodos usados para transmitir aos 
funcionários, novos e antigos, habilidades necessárias para o desempenho do trabalho." Segundo Reginatto (2004, p. 68), "o treinamento ajuda as pessoas a serem mais eficientes, evitando erros, melhorando atitudes e alcançando maior produtividade, pois, por meio dele, podia-se aprender fazendo, reavaliando e mudando comportamentos."

A forma ideal para o bom atendimento é que o atendente seja educado e honesto com o cliente. No caso do atendimento pessoal, em que estão frente ao cliente, necessita-se ser ainda mais cauteloso na forma de atender e servir, visto que se deslocou para resolver uma situação ou adquirir um produto/serviço.

Nem sempre todos tem essa disponibilidade, e até mesmo condição física ou econômica, para se dirigir ao local, algumas por questões de saúde ou até mesmo deficiência física necessitam resolver seus problemas de forma mais fácil.

Nos casos em que os clientes estão presencialmente no atendimento, faz-se necessário agilidade e prontidão das respostas. Para tal, os processos devem ser de fácil acesso e as resoluções mais pontuais, evitando respostas tardias. A espera por uma resposta ou sua ausência agrava a percepção acerca do atendimento recebido.

\section{FALTA DE TREINAMENTO}

Gil (2001, p. 115) ressalta que "para prepararem-se para os desafios da inovação e da concorrência, as empresas necessitam de pessoas ágeis, competentes, empreendedoras e dispostas a assumir riscos." Sendo assim, requer muito mais do que pessoas treinadas, precisa-se de pessoas engajadas no processo da empresa como um todo.

Por meio do treinamento Volpe e Lorusso (2009, p. 3) pontuam que "a pessoa pode adquirir informações e compreender habilidades, desenvolvendo, a partir destas, atitudes e comportamentos diferentes e novos conhecimentos."

Segundo Chiavenato (2009, p. 294) "o treinamento é uma maneira eficaz de delegar valor às pessoas, à organização e aos clientes. Ele enriquece o patrimônio humano das organizações". Sendo assim, se faz necessário um treinamento adequado para a equipe se sentir segura ao disponibilizar as informações.

Existem vários tipos de treinamento e cada um se encaixa em um tipo de negócio. Apresentam-se aqui, segundo o Portal de Educação, algumas técnicas de treinamento para esse grupo de atendentes pode ser:

- Discussão em Grupo: reunião bem planejada e com propósitos específicos. Embora possa ser utilizada em uma grande variedade de situações, é particularmente indicada quando o objetivo é criar ou modificar atitudes. A comunicação nos dois sentidos (instrutor treinandos) propicia maior troca e aprendizagem. As respostas e soluções devem partir dos treinandos com o incentivo do instrutor;

- Dramatizações (Role Playing): na dramatização os treinandos assumem papéis e representam as pessoas envolvidas em determinado caso. A dramatização apresenta a vantagem de possibilitar ao treinando a oportunidade de sentir a opinião e os sentimentos dos outros. $O$ instrutor precisa ter habilidade e experiência para conscientizar todos os envolvidos da importância do exercício e que se trata de um treinamento, sem o qual o exercício perde todo o sentido. A dramatização traz à tona aspectos emocionais que fazem parte de questões processuais;

- Simulações: é uma técnica usada geralmente para reprodução de um processo;

- Palestras: palestra também é um recurso muito usado tanto para levar o conhecimento aos colaboradores quanto para motivá-los a fazer um trabalho de excelência. (PORTAL EDUCAÇÃO, 2020, documento on-line)

As técnicas apresentadas contribuem para desenvolver a satisfação dos atendentes e ajudá-los a crescer profissionalmente dentro da sua área. Ressalta-se que os treinamentos acrescentam, deixando algo de bom para qualquer profissional. 


\section{ATENDIMENTO AO CLIENTE COM} OPORTUNIDADE DE MELHORIAS

As competências adquiridas por meio de treinamentos promovem melhorias para $o$ colaborador, para a empresa e para o cliente. De acordo com Bee (2000, p. 14), considerando a participação dos colaboradores em treinamentos relacionados ao atendimento ao cliente, "talvez seja importante ainda porque seu emprego depende da sobrevivência da empresa e você acha que o atendimento ao cliente é um elemento vital para essa sobrevivência". No entanto, entende-se que além desses motivos para se acreditar na importância do atendimento ao cliente, existem alguns outros um tanto pessoais (e até egoístas) para os quais deve-se estar atento:

- Clientes satisfeitos provocam menos estresse;

- Clientes satisfeitos tomam menos tempo;

- Cliente satisfeitos falam de sua satisfação para outras pessoas, que amplia uma boa reputação.

Ainda segundo Bee (2000, p. 43) "as oportunidades de melhorias seriam os benefícios citados, por isso se faz tão necessário a questão da promoção de treinamentos."

\section{HIPÓTESES DE SOLUÇÃO DO PROBLEMA}

Para Julião e Vandi (2008) "as consultas sobre as necessidades de treinamento devem ser contínuas e permanentes, e caracterizam-se por ser o primeiro passo na organização de um treinamento; entendendo a necessidade como situações que devem ser mantidas ou atingidas para o alcance de um objetivo."

Por meio dos aspectos desenvolvidos nas pesquisas realizadas, elencou-se as seguintes possibilidades de solução para os problemas detectados:

- Oferecer treinamento sobre os serviços que a empresa disponibiliza;

- Ter sempre um suporte (backoffice) para executar tarefas burocráticas;
- Incrementar programas que ofereçam o atendimento personalizado, porém virtual e telefônico realizado por essa mesma equipe de atendimento pessoal. Os recursos e plataformas oferecidas pela internet seria um agregado a esse atendimento.

\section{APLICAÇÃO À REALIDADE}

A partir da análise das hipóteses de solução, de uma reflexão acerca dos fatores imediatos e das condicionantes maiores, bem como do contexto no qual se encontra o problema em questão, foi possível eleger algumas contribuições para a solução do problema apresentado com o objetivo de intervir na realidade de modo a buscar o atendimento às necessidades do cliente e da empresa.

Já que o treinamento é voltado para a preparação dos funcionários e suas competências, indica-se uma ação para melhorar a qualidade de vida do funcionário, técnicas de atendimento e sugestões acerca de como facilitar o atendimento, tanto para o funcionário quanto para o cliente.

A maioria dos autores entendem que as etapas do processo de treinamento são divididas em quatro fases: diagnóstico (levantamento de necessidades de treinamento), programação ou planejamento, implementação ou execução e avaliação.

A primeira etapa, ou o primeiro passo para a abordagem no treinamento, é dar conhecimento aos envolvidos sobre o que é um atendimento de qualidade. Estar disponível a ouvir o cliente e atender suas necessidades é, com certeza, a primeira etapa para um atendimento de qualidade.

Uma segunda etapa do treinamento será a de oferecer conhecimento técnico sobre as informações que $o$ atendente deve disponibilizar ao cliente referente ao que é solicitado. $\mathrm{O}$ atendente tem que, obrigatoriamente, ter conhecimento sobre processos administrativos e do que ele pode informar ou não. Muitas informações são sigilosas e outras são informações essenciais para o conhecimento do cliente sobre o produto/informação que ele deseja adquirir.

Nessa etapa o chefe do setor oferece todas as informações técnicas, jurídicas e ferramentas 
tecnológicas relacionadas à realização da atividade. Por meio da exposição de uma apresentação o facilitador pode mostrar os documentos corretos a serem usados, as informações necessárias a serem informadas ao cliente e outras demandas de rotina a serem executadas para finalizar o processo com perfeição.

Essa etapa será de grande importância, pois um processo de atendimento bem realizado apoia na inibição os erros. Um atendimento em que os processos são mal executados gera desgaste para o cliente e muitas vezes os erros difíceis de serem corrigidos.

$\mathrm{Na}$ terceira etapa e final do treinamento, será oferecido pela empresa ao funcionário o apoio emocional para que ele tenha equilíbrio ao atender o cliente.

Clot relata que é importante superar constrangimentos e conflitos:

Trata-se de fazer uma auto análise do trabalho, consagrando todos os esforços à busca de um só objetivo: aumentar o poder de ação dos coletivos de trabalhadores sobre o ambiente de trabalho real e sobre si mesmos. A tarefa consiste, então, em inventar ou reinventar os instrumentos desta ação, não mais protestando contra os constrangimentos, mas pela via de sua superação concreta." (CLOT, 2001, p.9)

É irrelevante que um atendente tenha todos os conhecimentos técnicos e humanizados se ele mesmo não está bem preparado para lidar com as adversidades, como por exemplo ser mal tratado pelo cliente. $\mathrm{O}$ atendente precisa desenvolver $\mathrm{O}$ equilíbrio emocional para as situações desagradáveis que possam ocorrer. A empresa deve possuir uma estrutura de apoio com cuidados emocionais e físicos desse atendente, garantindo a ele um devido suporte.

A fase final do treinamento deverá ser concluída utilizando dinâmicas de grupo que estimulem a criatividade e intuição da equipe. Vale-se também a aplicação de testes comportamentais para avaliar individualmente cada participante. Para sua consolidação, sugere-se a realização de uma palestra motivacional para que todos saiam energizados e com mais vontade de desempenhar seu papel de atendente com excelência.
Frente ao diagnóstico realizado referente à necessidade de treinamento a programação deverá ser avaliada considerando os melhores dias e horários, além da necessidade de dividir a equipe em turmas menores para o treinamento, assim os departamentos não ficarão descobertos. Deve-se avaliar também a possibilidade de realização de cursos na modalidade on-line e os investimentos financeiros para tal.

\section{CONSIDERAÇÕES FINAIS}

Para Gonçalves (2018, p. 7) "é indiscutível que a excelência no atendimento ao cliente é um dos maiores diferenciais competitivos do mercado e o fator principal para o crescimento das vendas e a evolução das empresas. Não existe empresa estabilizada que prospere e conquiste mercado sem clientes satisfeitos." Frente à essas ponderações é possivel compreender a dimensão e potencial do atendimento para fidelização, retenção e busca de novos clientes, também refletido no segmento educacional.

Manter a equipe alinhada com propósitos comuns e um atendimento com excelência percebida é um grande desafio e exige constantes análises e ações. Evidencia-se, assim, o treinamento como uma alternativa que traz bons resultados.

Treinamento é a chave. Em uma época em que o sucesso dos negócios tem à frente o atendimento e na base o foco no cliente, conhecer plenamente o potencial dos colaboradores pode ser um bom caminho a ser trilhado. Treinar é acima de tudo valorizar o funcionário e prepará-lo para, também, valorizar o cliente. (GONÇALVES, 2018, p. 3)

0 atendimento humanizado em que existe cordialidade, atenção e o atendente se importa com o problema do cliente, são premissas para conquistar, manter e divulgar a empresa.

Por meio desse estudo foi possível detectar lacunas oportunas no atendimento de uma instituição de ensino em uma cidade do interior de Minas Gerais e, a partir delas, realizar o aprofundamento por referências de estudos e pesquisas sobre a temática, levando, assim, à possíveis hipóteses de solução. Em virtude da pandemia da COVID-19 não foi se possível 
a aplicação do plano de ação proposto, porém foi direcionado à gestão da instituição para que possa promover sua intervenção em um momento oportuno.

\section{REFERÊNCIAS}

BEE, Roland. Fidelizar o cliente. Você SA. NBL Editora, 2000.

CHIAVENATO, Idalberto. Gestão de pessoal: o novo papel dos recursos humanos nas organizações. Rio de Janeiro: Campus, 2009.

CLOT, Y. A função psicológica do trabalho.

Petrópolis: Editora Vozes. Tradução de Adail Sobral, 2001.

DESSLER, G. Administração de recursos humanos.

2. ed. Tradução de Cecília Leão Oderich. São Paulo: Pearson Prentice Hall, 2003.

GIL, Antônio Carlos. Gestão de pessoas: enfoque nos papeis profissionais. São Paulo: Atlas. 2001.

GONÇALVES, Albírio. Excelência no atendimento: atraindo, convertendo e fidelizando clientes. 2018.

HAMBLIN, A. Avaliação e controle do

treinamento. São Paulo: McGraw-Hill do Brasil, 1979.

KOTLER, P.; ARMSTRONG, G. Princípios de

Marketing. São Paulo: Pearson/Prentice Hall. 2003.

JULIÃO, B. E.; VANDI, A. M. Diferenças entre treinamento, desenvolvimento e aprendizagem. Grupo de estudo em ABRH, 2008. Disponível em: http://www.abrhrs.com.br/2008/grupos-artigosmostrar.php?cod=101. Acesso em: 27 maio 2020.

MILKOVICH, G. T.; BOUDREAU, J. W. Administração de recursos humanos. São Paulo: Atlas, 2010.

Portal Educação, Técnicas de treinamento.

Disponível em:

https://siteantigo.portaleducacao.com.br/conteud o/artigos/administracao/tecnicas-de-

treinamento/32112. Acesso em 03 maio 2020.
REGINATTO, Antonio Paulo. Equipes campeãs: potencializando o desempenho de sua equipe. 2 . ed. Porto Alegre: SEBRAE/RS, 2004.

TANI, Ramos, Z. Atendimento ao Público. São Paulo: Ética, 2018.

VOLPE, Renata; LORUSSO, Carla. A importância do treinamento para o desenvolvimento do trabalho. Disponível em:

https://www.psicologia.pt/artigos/textos/TL0136.p df. Acesso em: 06 maio 2020. 